\title{
SCIENCE: UW-NPS PeRSPECTIVES
}

\author{
MARK S. BOYCE \\ DIRECTOR — UW-NPS RESEARCH CENTER
}

"... ever since I was old enough to be cynical I have been visiting national parks, and they are a cure for cynicism, an exhilarating rest from the competitive avarice we call the American Way."

-Wallace Stegner

We have chosen to feature Lederman's (1991) article entitled "Science: The end of the frontier?" because it addresses several issues of interest to researchers, particularly those who are funded through the University of Wyoming-National Park Service (UW-NPS) Research Center. And we think that it is appropriate to respond by discussing the Research Center's policy related to some of these issues.

Lederman notes that American science is losing ground and that for several reasons academic research in the United States is in a depressed state. Many of these reasons affect UW-NPS researchers directly, and substantial reforms will be necessary before the situation improves very much. I will not claim to resolve the burdens which face researchers attempting to work in national parks, but rather I will discuss the issues raised by Lederman in the context of our program.

Research is fundamental to accomplishing the mission of the National Park Service. It is clear that the NPS must have solid research on which to base management, e.g., such research will be necessary to deal with external threats to park resources (Freemuth 1991: p. 136). The NPS does not have an explicit mandate from congress that includes research, and therefore, we find that NPS justifies research as a support service for resource management.

\section{$\downarrow \quad$ Funding}

A common complaint coming from researchers is that they do not have adequate funding to conduct the research they wish to pursue. Indeed, the availability of funding is an acute problem in our efforts to meet the long list of resource management needs for research. It is the objective of the UW-NPS Research Center to attempt to secure the best research possible for the limited dollars available.

We begin our process by soliciting input from resource management specialists from throughout the Rocky Mountain Region on research needs in their respective parks. The resource management specialists then meet to set priorities for this list, and we fund as many projects as possible. Our usual funding level is $\$ 16,000$ per year on field-based projects with the rationale that this is adequate to fund a graduate-student stipend for one year plus $\$ 5,000$ to $\$ 7,000$ for field and travel expenses.

To my mind, it is a serious threat that we sometimes advertise projects at funding levels which would require compromising the quality of the science. For example, because of limits to funding the investigator may not be able to secure adequate sample sizes, or equipment may be less than optimal. Yet, 
from a resource management specialists' perspective, some information is better than no information, therefore it may be better to use available funds for a research effort even if the effort is inadequate. Often resource management decisions must be made irrespective of the availability of relevant scientific research.

This creates a serious dilemma and I share the concerns of both researchers and managers. When we advertise a project with "Available Funds" below that necessary to conduct the research, it is essential that a researcher resolve the availability of outside resources before embarking on such a study. If a project requires radio-telemetry equipment or specialized equipment for conducting chemical analyses, but "Available Funds" are inadequate to purchase these items, it is implicit that we expect the researcher to obtain such equipment by other means. This clearly gives an edge to a researcher who already has such equipment in his or her laboratory.

Similarly, researchers who live great distances from the park unit may have travel expenses which make it prohibitively expensive to compete for a particular project. Again, this gives an edge to investigators who live closer to the study area.

But neither of these constraints imply that we cannot secure the needed research with the dollars available. Rather, it narrows the field and means that only a few researchers (or sometimes none) will be able to develop a competitive proposal for the "Available Funds."

An important role of the UW-NPS Research Center is to encourage outside sources of support for research in parks of the Rocky Mountain Region. Researchers often come to us with proposals that include funding from outside sources to supplement their budgets. And we have succeeded in bringing in funds from the State of Wyoming, the Montana Department of Fish, Wildlife and Parks, the U.S.D.A. Forest Service, the U.S. Fish and Wildlife Service, the U.S. Geological Survey, and other non-NPS funds to enhance research in national parks.

Indeed, amongst the 65 proposals which we received in response to our spring 1991 request for proposals competition, a total of 36 or $55 \%$ offered outside support. These supplemantal funds totalled $\$ 1,325,148$ compared with requests for UW-NPS Research Center funds totalling $\$ 1,456,650$. In reality there is outside support on virtually all proposals if one takes into consideration faculty salaries, vehicles and equipment provided by investigators, etc. These are research dollars committed to research in our national parks which are attracted by the competitive program.

I would be remiss if I did not point out that the parks themselves foster interest in research. Many people return year-after-year with only outside funding for the opportunity to work in some of the most spectacular landscapes in the world.

\section{Overhead}

Universities typically charge overhead on research grants and contracts to assist with capital investments and maintenance of research facilities. The rate of overhead charge ranges from $35-80 \%$ depending upon the university. These rates are audited by the federal government, and are readily justified. Indeed, I suspect that university indirect costs will be particularly well justified since the recent imbrogilio over Stanford's overhead rates.

Yet, park scientists and administrators often complain about the overhead charges requested by universities, noting that more research could be accomplished if the overhead were not required. Furthermore, park research often is conducted in the field and it is difficult for park-based scientists to justify expending substantial funds to maintain resources on a campus. But such a view overlooks the fact that if the park were to maintain equipment and staff to be able to conduct the same research, the costs would be exorbitant! It is extremely expensive to maintain research staff and equipment; to do so in the diversity of areas of expertise needed by the NPS is certainly not feasible at current funding levels.

The UW-NPS Research Center has a policy that universities will be allowed to charge no more that $10 \%$ overhead. Although this is substantially less than the going overhead rate for every university that has ever received funds from the Research Center, we have yet to have a university decline funding because the overhead rate was too low. The National Park Service has successfully negotiated $10 \%$ indirect costs on park research and cooperative agreements at universities throughout the country (Office of the Inspector General 1990).

My interpretation of this is that university 
administrators recognize that university faculty will be occupying space and using university resources whether or not they are funded. Thus it is better to secure $10 \%$ overhead for a research project than none at all. A major consideration is that reduced overhead is made less painful by the fact that a proportion of park research is conducted off-campus.

Our cap on overhead has reduced substantially the concerns of park scientists and administrators who do not like to see project funds diverted for intangibles such as overhead. I am unwilling to argue that the UW-NPS Research Center should be free from indirect costs, but nevertheless most universities are willing to allow their faculty to conduct park research at reduced rates. Furthermore, the national parks are valuable resources in many of the western states, and by supporting research in national parks which may occur within the state where the university occurs, the university is supporting a resource which brings tourist dollars and development to the state. Of course private institutions will not share such a mission.

\section{$\downarrow \quad$ RePORTINg REQUiREMENTS}

We frequently hear complaints about the extent of reporting requirements for projects funded through the Research Center. Indeed, I have struggled to meet the Research Center's reporting requirements myself because some of my research was funded by the Research Center before I became Director of the program. The Research Center requires a semi-annual report, an annual report, annual continuation proposals for multi-year studies, a draft final report and a final report. In addition, the park will require an "Annual Investigators' Report," and the investigator may be requested to submit a popular article for Park Science or similar publication. For a typical 3-year study, this means that 13-14 proposals and/or reports are required; 5-6 for a single-year study. All of the paper involved is a burden for everyone.

We acknowledge the problem, and in recent years UW-NPS has reduced reporting from quarterly to semi-annual reports. The Research Center itself is obligated to produce an Annual Report, but whenever possible we try to use semi-annual or executive summaries from final reports to minimize duplication. In addition, just last year the Rocky Mountain Region NPS Science Office eliminated the draft annual report from the reporting requirements. Most of the reports that are required are the minimum necessary according to federal procurement regulations.

One approach which we encourage is to submit copies of manuscripts submitted for publication as part of the text to meet semi-annual and annual reporting requirements. This hastens publication of results, and reduces duplication of effort.

\section{$\downarrow$ Competition}

Lederman (1991) points out that there are presently twice as many doctoral-level scientists competing for research dollars as in 1968. This means that there can be stiff competition for the funds available. Competition is made even more vigorous because many university administrators measure the success of a researcher in part by the grant or contract dollars brought into the university. Indeed, rewards to faculty sometimes appear to be based more directly on the dollars in overhead which are attracted to the university!

Academics are accustomed to being rewarded for ideas. Proposals to the National Science Foundation or the National Institutes of Health are more likely to be funded if the principal investigator has a clever idea or a new approach to a problem. This runs counter to the RFP approach used for most projects funded through the Research Center, where the problem of interest is specified by the RFP. We have loosened this up a little by offering an unsolicited proposals option funded by the State of Wyoming for scientists with a project in Wyoming or based at a Wyoming research institution. I feel strongly that the NPS can benefit from good ideas coming from researchers and that a grants program would allow the NPS to take advantage of such ideas. However, as I noted above, the NPS presently does not have a research mandate, and research is viewed as a service to resource management-certainly not an end unto itself.

Despite the frustrations that it may present, competition is fundamental to ensuring good science. Stiff competition amongst researchers increases the quality of proposals and thereby the quality of the research being conducted. Indeed, it is this principle which motivates the fundamental reason for the Research Center's existence; a fact which has been applauded by a recent audit by the Office of the 
Inspector General on Cooperative Agreements within the National Park Service (Office of the Inspector General 1990). It is our intent to ensure that anyone in a university community has equal opportunity to compete for the available funds to conduct research in our national parks. It is the quality of the science and not the institutional affiliation which determines who gets funded.

\section{REgULATORY REQUIREMENTS}

Animal care, Office of Management of the Budget (OMB) approval for public survey instruments (questionnaires), hazardous substance and waste disposal restrictions, back-country permits, and regulations on curation of collections are but a sample of the regulations facing those researchers planning to work in one of the national parks. As pointed out by Lederman, such burdens reduce productivity and consume vast amounts of time that researchers could use more productively. Yet we all recognize the need for many of these regulations.

It has been my experience that there are many individuals working for the NPS who can be of great help in meeting some of these regulatory requirements. For example, becoming well acquainted with the relevant district ranger will invariably save the researcher many hassles and can offer many benefits.

\section{The Future}

I do not believe that many of Lederman's remarks apply to natural resources research. Although it may well be true that the United States is facing stiff international competition in technology development and research, in the various natural resource disciplines, American science still provides the leadership which will guide natural resource management into the forseeable future. Nevertheless, we all share Lederman's concerns for the inadequacy of government support for research and technological advance.

Priorities are changing and society is becoming more cognizant of the consequences of mismanagement of natural resources. As public understanding of natural resources increases, the message of the NPCA's "Gordon Report" will become more poignant: "the NPS cannot manage what it does not understand" (Gordon et al. 1989). Yet, management will take place whether we understand the resource or not. But more and more, the public will not tolerate uninformed management. It is the purpose of the UW-NPS Research Center and science programs in the NPS to improve our understanding of natural resources so that management can be better.

The Director of the National Park Service, James Ridenour, has made a strong commitment to science in the national parks (Ridenour 1990). In addition, he has charged a prestigious National Research Council committee of the National Academy of Sciences with reviewing NPS science-a move which can only improve the quality of science. There is every reason to believe Huff's (1990) optimistic view for the future of park science.

To conclude, I think that it takes a special sort of person to conduct field research in our national parks. There are many difficulties including back-country work, tourists, permits, ... But we all know why we contend with these frustrations: the national parks are very special places, the crown jewels of America, our national treasures. And there are special rewards for those of us who work there.

\section{$\downarrow$ ACKNOWLEDGEMENTS}

Thanks to Tom Buchanan, Marshall Gingery, Derek Hodgson, Dan Huff, Bob Keiter, Evie Merrill, Glenn Plumb, and Robert Schiller for comments and discussion.

\section{$\downarrow \quad$ Literature Cited}

Freemuth, J. C. 1991. Islands under siege: National Parks and the politics of external threats. Univ. Press of Kansas, Lawrence. 186pp.

Gordon, J. C. et al. 1989. National parks: From vignettes to a global view. National Parks and Conservation Association, Washington, D.C.

Huff, D. 1990. Guest column. Res. Center Rep. 1:4.

Lederman, L. M. 1991. Science: The end of the frontier? Science (suppl.) 1991:1-20.

Office of the Inspector General. 1990. Review of cooperative agreements awarded by the National Park Service. Audit Report no. 90-79. U.S. Department of Interior, Washington, D.C. 48pp. 